\title{
ESTIMULAÇÃO MECÂNICO-TÉRMICA DOS PILARES PALATOGLOSSO
}

\author{
Maria de Fátima Lago ALVITE, Renata Lobbé Cotta LOPES e Milton M. B. COSTA
}

RESUMO - Racional - Os pilares palatoglosso foram admitidos como a principal sede dos receptores responsáveis por iniciar a fase faríngea da deglutição. Essa fase reflexa iniciar-se-ia em resposta ao estímulo produzido pelo progresso do bolo e da língua em sentido posterior. Esses conceitos deram base à manobra mecânico-térmica que visa estimular os receptores desses pilares, produzindo respostas motoras capazes de potencializar a recuperação da função faríngea comprometida. O conceito de possível resposta motora ao estímulo desses pilares, embora comum, não é unanimemente aceito. Objetivo - Verificar as possíveis respostas motoras produzidas pelo estímulo mecânicotérmico sobre os pilares palatoglosso. Métodos - Por entender que indivíduos sadios são capazes de prover respostas reflexas mais efetivas do que as que seriam obtidas em pacientes, avaliaram-se 51 voluntários adultos sadios de ambos os sexos reproduzindo o estímulo sobre os pilares, usando sonda metálica de ponta romba resfriada em água mantida a $10^{\circ} \mathrm{C}$. Resultados e considerações - $\mathrm{O}$ estudo mostrou que o estímulo mecânico-térmico sobre os pilares não foi capaz de produzir qualquer resposta motora envolvida na dinâmica da fase faríngea da deglutição. É possível que as respostas contráteis observadas em alguns estudos devam-se ao reflexo de gag inadequadamente interpretado ou a contrações voluntárias inconscientes por esforço de manutenção da abertura da boca e externalização da língua durante a exposição dos pilares para execução da manobra de estimulação mecânico-térmica.

DESCRITORES - Faringe, fisiologia. Deglutição. Estimulação física. Engasgo. Transtornos de deglutição.

\section{INTRODUÇÃO}

Os músculos palatoglosso inseridos, a cada lado, na aponeurose palatina e na base da língua, formam arco com função esfinctérica. Revestidos pela mucosa, os músculos palatoglosso definem pilares, também denominados como anteriores, que ajustados sobre o contorno do dorso lateral da língua, separam as cavidades oral e faríngea ${ }^{(5,6,7)}$.

Durante a deglutição o conteúdo oral em transferência para a faringe, produz estímulo que resulta em complexo mecanismo reflexo que coordena a seqüência muscular contrátil responsável pela condução do bolo da faringe para o esôfago ${ }^{(4,5,6,14,23,27)}$.

A localização de receptores capazes de gerar impulsos aferentes nas diferentes áreas das cavidades oral e faríngea, sugere, em relação àqueles localizados nos pilares anteriores, a concepção de que seriam os mais sensíveis. Esse conceito apresentado por POMMERENKE ${ }^{(22)}$ baseiase na descrição de WASSILIEFF(28) que não encontrou uma área específica que, por estímulo isolado, fosse capaz de eliciar o reflexo da deglutição ${ }^{(22)}$. Não obstante, pôde observar bloqueio de toda resposta reflexa após deglutição de esponja saturada com solução de cocaína.

Embora se admita não estar claramente definido se a resposta faríngea da deglutição seria resposta reflexa em cadeia ou toda uma seqüência programada como uma unidade por centro encefálico ${ }^{(20)}$, considerou-se ser essa resposta iniciada pelo estímulo de receptores localizados na região do pilar anterior produzida pelo avanço do bolo e da língua ${ }^{(12,14)}$. Os impulsos aferentes, provindos em especial da região dos pilares, seriam conduzidos ao tronco cerebral atingindo inter-neurônios ligados ao centro medular da deglutição, que coordenaria a geração de impulsos eferentes responsáveis pela motricidade da fase faríngea da deglutição ${ }^{(1,2,14,20,22)}$.

$\mathrm{O}$ conceito de que sejam os pilares anteriores (palatoglosso) a sede da maior sensibilidade aferente e que a resposta faríngea iniciar-se-ia por seu estímulo, por certo embasa a manobra terapêutica de estimulação mecânica com sonda resfriada a ser efetuada sobre ele, com vistas à recuperação funcional da deglutição. $\mathrm{O}$ objetivo admitido é o de estimular os receptores do reflexo de deglutição no arco palatoglosso ${ }^{(14)}$. Essa manobra tem sido indicada, em especial, para pacientes com disfagia de origem neurológica e aqueles submetidos a cirurgia

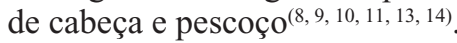

Considerou-se que o estímulo mecânico do pilar seria "sabidamente capaz" de auxiliar os pacientes com encurtamento da duração da fase faríngea da deglutição ${ }^{(14)}$. Foram registradas por eletromiografia de superfície da região cervical efetivas respostas motoras ao estímulo mecânico sobre o pilar palatoglosso e admitido que esse estímulo pode eliciar, de modo reprodutível, respostas provindas do sistema nervoso central ${ }^{(9)}$.

FUJIU et al. ${ }^{(9)}$ valorizam como reação associada à resposta à estimulação mecânica do pilar, o fato de 10 ,

Laboratório de Motilidade Digestiva/Imagem do Instituto de Ciências Biomédicas da Universidade Federal do Rio de Janeiro, RJ.

Correspondência: Dr. Milton M.B. Costa - Laboratório de Motilidade Digestiva e Imagem, Departamento de Anatomia, Universidade Federal do Rio de Janeiro ICB/CCS/ UFRJ - 21941-590 - Rio de Janeiro, RJ, Brasil. E-mail: mcosta@acd.ufr..br 
entre 30 indivíduos testados, admitirem o desejo de deglutir. Consideram ainda que estímulos mecânicos repetitivos, aplicados sobre o pilar anterior seriam capazes de evocar respostas no complexo supra e infra hióideo.

A associação de estímulo térmico (frio) ao mecânico, sobre os pilares anteriores, foi admitida como capaz de promover um mais rápido disparo da fase faríngea da deglutição ${ }^{(1,2,18)}$. LAZZARA et al. ${ }^{(15)}$ admitiram ter encontrado evidências clínicas de efetiva reposta à estimulação térmica sobre os pilares. O conceito de somatória de estímulos foi ampliado por SCIORTINO et al. ${ }^{(24)}$, que acrescentaram ao mecânico-térmico o estímulo gustativo, admitindo efeito cumulativo capaz de potencializar o tempo de resposta da deglutição.

Ao lado de uma potencialização da fase faríngea da deglutição como resposta produzida por estímulo direto sobre os pilares anteriores, tem-se também admitido respostas motoras isoladas como elevação do palato mole ou da cartilagem tireóidea ou ainda contração dos pilares ${ }^{(10,12,18,19)}$.

Foi considerado que, embora a literatura seja controversa com relação à efetividade das manobras de estímulo do pilar anterior, pode-se claramente observar a resposta desta estimulação, em pacientes irradiados ou com edemas intensos pós-operatórios na área do pilar e em áreas vizinhas ${ }^{(3)}$.

A morfologia e a fisiologia que regem a percepção, a condução e a resposta motora reflexa da faringe, encontrada em indivíduos sadios, é a mesma que dá base à crença de efetividade para as manobras, mecânica e ou mecânico-térmica, propostas como terapêutica nas disfagias. Desse modo, uma resposta melhor coordenada, mais evidente e efetiva deve ser esperada e obtida na avaliação de indivíduos nos quais a organização morfofuncional, ligada à deglutição, esteja preservada. Baseados nesse princípio, buscou-se identificar, em indivíduos sadios, a presença de possíveis respostas motoras passíveis de estarem associadas ao estímulo mecânico-térmico do pilar palatoglosso.

\section{MÉTODOS}

Avaliaram-se 51 voluntários adultos sadios de ambos os sexos, com idades entre 18 e 74 anos. Quatro desses indivíduos eram amidalectomizados. Nenhum dos voluntários apresentava dificuldade de abertura da boca ou exacerbada reação à introdução do instrumento de toque na cavidade oral. Todos foram informados sobre os propósitos e metodologia do estudo e assinaram termo de consentimento livre e esclarecido.

A estimulação a ser procedida foi a mecânico-térmica. A área a ser estimulada foi a dos pilares palatoglosso. $\mathrm{O}$ instrumento de estímulo foi sonda metálica de aço maleável com ponta romba e superfície de toque de $0,3 \mathrm{~mm}$ de diâmetro, resfriada por imersão em água com gelo e mantida a $10^{\circ} \mathrm{C}$ controlados por termômetro infravermelho TD-960 ICEL.

Durante o estudo, os voluntários se sentaram e apuseram o dorso e a região occipital contra superfície plana com leve extensão cervical. Informados passo a passo sobre os procedimentos, os 18 primeiros voluntários foram solicitados a abrir a boca e posicionar a língua de modo a permitir maior facilidade de visualização e toque dos pilares. Os 33 voluntários seguintes foram avaliados com a boca em aberturas confortável e máxima. Em cada um desses dois tipos de abertura da boca, os voluntários foram testados com a língua internalizada e externalizada (Figuras 1 e 2)
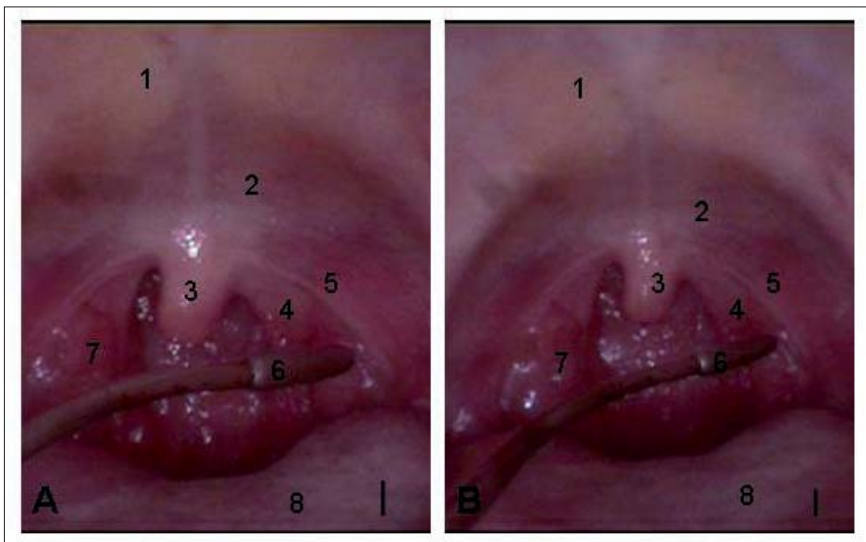

FIGURA 1. A (abertura confortável), B (abertura máxima) obtidas por exposição da cavidade oral de um mesmo voluntário, onde a barra vertical, que representa $3 \mathrm{~mm}$, deixa ver ampliaçōes distintas. Os números identifican os mesmos elementos em A e B: 1 - palato duro, 2 - palato mole, 3 - úvula, 4 - pilar posterior (palatofaríngeo), (amigdala palatina) e 8 - dorso da lingua Observar a maior tensão do palato mole em B. O dorso da lingua de ver concavidade látero-lateral por depressão de seu centro produzida intuitivamente pelo voluntário solicitado abrir a boca para exposição do pilar em A e B

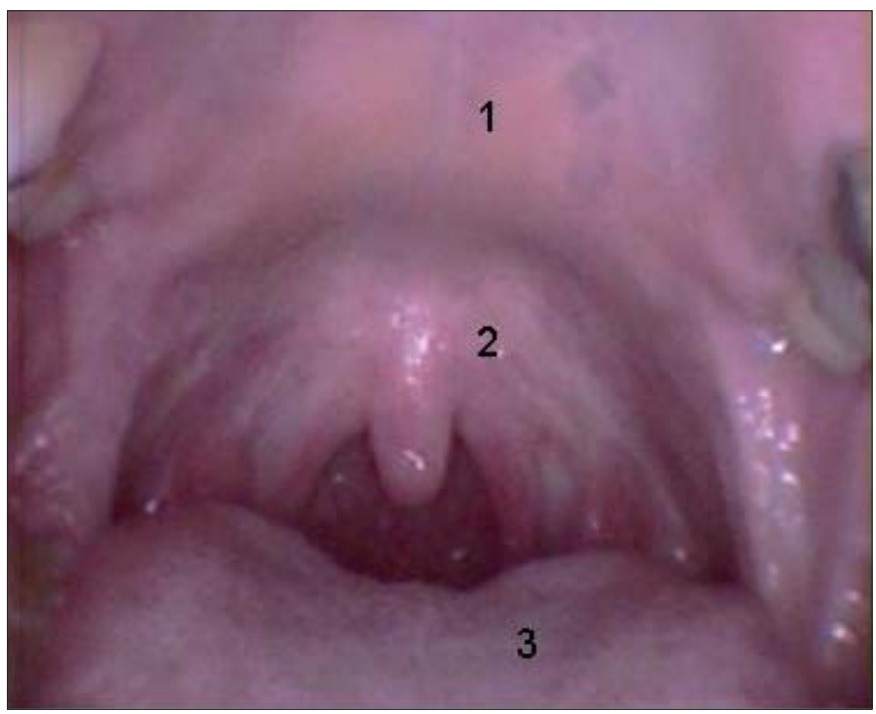

FIGURA 2. Figura obtida por abertura da cavidade oral, onde 1 - palato duro, 2 - palato mole e 3 - dorso da língua. Observar a maior tensão do palato mole semelhante ao observado em B na Figura 1 aqui produzida
por abertura máxima da boca para exposição do pilar. Associada à contração do tensor do palato, o dorso da
língua deixa ver concavidade látero-lateral por depressão de seu centro devido à contração de sua musculatura, à semelhança do observado em A e B da Figura

A introdução da sonda metálica resfriada na cavidade oral foi efetuada por condução manual até a altura do pilar, onde três toques seqüenciais foram realizados sobre sua base em um lado a cada vez, sem que outras estruturas fossem tocadas durante toda a execução da manobra. Esse procedimento foi denominado manobra "com toque". Após o primeiro teste, a sonda era resfriada e reintroduzida na cavidade oral, como se nova série de estímulos fosse ser produzida, sem que o pilar, no entanto, fosse efetivamente tocado. Esta manobra foi denominada manobra "sem toque". Os indivíduos não eram 
previamente informados se haveria toque ou não no momento da manobra.

As respostas aos estímulos foram observadas e registradas de modo independente por dois examinadores que construíram a Tabela 1, que registrava os resultados obtidos com a língua internalizada e externalizada com abertura confortável da boca, com toque e sem ele, e outra (Tabela 2) que registrava os mesmos parâmetros com a boca, em abertura máxima. A observação dos 18 primeiros voluntários foi alocada naquela tabela e condições em que sua avaliação foi procedida.

\section{RESULTADOS}

Dos 18 primeiros voluntários solicitados a abrir a boca e posicionar a língua de modo a permitir maior facilidade de visualização e toque dos pilares, 9 permitiram avaliação em dimensão menor que a máxima e língua internalizada, 4 nesta mesma dimensão com língua externalizada, 2 com abertura máxima e língua internalizada e $3 \mathrm{com}$ abertura máxima e língua externalizada.

$\mathrm{Na}$ presente amostra não foi possível observar diferenças passíveis de serem atribuídas a sexo ou idade.

Além das observações buscadas, uma vez referidas pela literatura como possíveis, foram listadas na coluna "observações" das Tabelas, eventos motores como movimentação de língua, movimentação de língua com movimentação de pilar e movimentação de língua com movimentação de palato mole, por terem eles sido identificados como presentes em algum momento.

Sete itens foram listados com vistas à observação de seu surgimento, como dependência do estimulo mecânico-térmico em um ou em ambos os pilares: 1. deglutição, 2. elevação da cartilagem tireóide, 3. movimento isolado do palato mole, 4. movimento isolado

TABELA 1. Estímulo mecânico-térmico - boca em abertura confortável

\begin{tabular}{|c|c|c|c|c|c|c|c|c|c|c|}
\hline \multirow{4}{*}{ Observações } & \multicolumn{3}{|c|}{ Língua internalizada } & \multicolumn{2}{|c|}{$\mathrm{n}=42$} & \multicolumn{3}{|c|}{ Língua externalizada } & \multicolumn{2}{|c|}{$\mathrm{n}=37$} \\
\hline & \multicolumn{3}{|c|}{ Com toque em ambos os pilares } & \multicolumn{2}{|c|}{ Sem toque } & \multicolumn{3}{|c|}{ Com toque em ambos os pilares } & \multicolumn{2}{|c|}{ Sem toque } \\
\hline & \multicolumn{2}{|c|}{ Pres. } & \multirow{2}{*}{ Aus. } & \multirow{2}{*}{ Pres. } & \multirow{2}{*}{ Aus. } & \multicolumn{2}{|c|}{ Pres. } & \multirow{2}{*}{ Aus. } & \multirow{2}{*}{ Pres. } & \multirow{2}{*}{ Aus } \\
\hline & Conduçäo & Toque & & & & Conducäo & Toque & & & \\
\hline 1. Deglutição & - & - & 42 & - & 42 & - & - & 37 & - & 37 \\
\hline $\begin{array}{l}\text { 2. Elev. Cartilagem } \\
\text { tireóidea }\end{array}$ & - & - & 42 & - & 42 & - & - & 37 & - & 37 \\
\hline $\begin{array}{l}\text { 3. Mov. isolado do } \\
\text { palato mole }\end{array}$ & - & - & 42 & - & 42 & - & - & 37 & - & 37 \\
\hline $\begin{array}{l}\text { 4. Mov. isolada do } \\
\text { pilar anterior }\end{array}$ & - & - & 42 & - & 42 & - & - & 37 & - & 37 \\
\hline 5. Mov. língua isolada & $\begin{array}{c}8 \\
(19 \%)\end{array}$ & - & 34 & $\begin{array}{c}7 \\
(16,66 \%)\end{array}$ & 35 & $\begin{array}{c}10 \\
(27 \%)\end{array}$ & - & 27 & $\begin{array}{c}8 \\
(21,62 \%)\end{array}$ & 29 \\
\hline $\begin{array}{l}\text { 6. Mov. língua associada } \\
\text { Mov. pilar anterior }\end{array}$ & $\begin{array}{c}2 \\
(4,76 \%)\end{array}$ & - & 40 & $\begin{array}{c}1 \\
(2,38 \%)\end{array}$ & 41 & - & - & 37 & - & 37 \\
\hline $\begin{array}{l}\text { 7. Mov. língua associada } \\
\text { Mov. pal. mole }\end{array}$ & $\begin{array}{c}4 \\
(9,5 \%)\end{array}$ & - & 38 & $\begin{array}{c}7 \\
(16,66 \%)\end{array}$ & 35 & $\begin{array}{c}4 \\
(10,81 \%)\end{array}$ & - & 33 & $\begin{array}{c}5 \\
(13,51 \%)\end{array}$ & 32 \\
\hline
\end{tabular}

Distribuição das observações esperadas por estímulo mecânico-térmico do pilar anterior com língua internalizada e externalizada com boca em abertura confortável. Buscou-se observar respostas motoras produzidas com e sem 0 estímulo direto dos pilares

TABELA 2. Estímulo mecânico-térmico - boca em abertura máxima

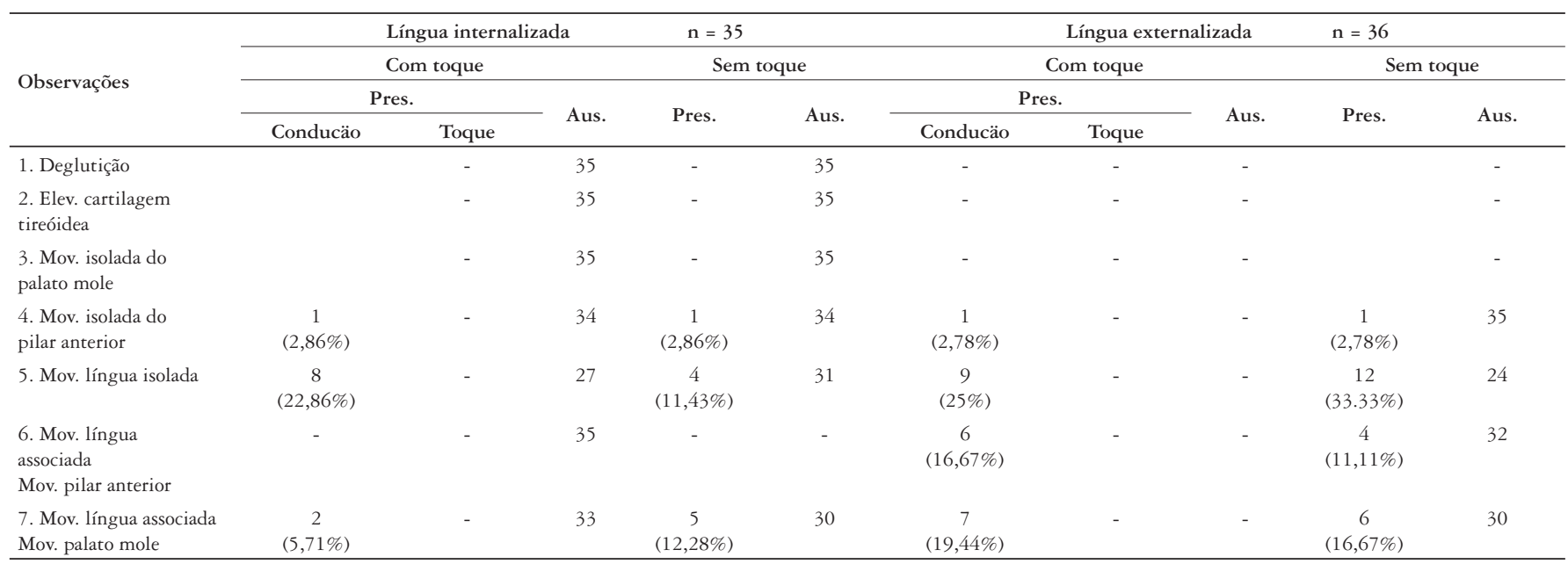

Distribuição das observaçōes esperadas por estimulo mecânico-térmico do pilar anterior com língua internalizada e externalizada com boca em abertura maxima. Buscou-se observar respostas motoras produzidas com e sem o estimulo direto dos pilares. 
do pilar anterior, 5. movimento isolado da língua, 6. movimento da língua associado ao movimento do pilar anterior, e 7. movimento da língua associado ao movimento do palato mole.

Com o efetivo estímulo mecânico-térmico sobre um ou ambos os pilares não foi possível observar qualquer das sete respostas aguardadas em nenhum dos 42 indivíduos com língua internalizada e boca com abertura confortável, em nenhum dos 37 com língua externalizada e abertura confortável da boca, em nenhum dos 35 com língua internalizada e abertura máxima da boca e em nenhum dos 36 com língua externalizada e boca com abertura máxima.

Sem que se tenha produzido o efetivo estímulo mecânicotérmico sobre os pilares, pôde-se observar nas manobras definidas como "sem toque", a presença de movimentos isolados da língua, bem como movimentos associados da mesma com o pilar anterior e com o palato mole. Esses movimentos foram observados tanto com a língua internalizada, quanto externalizada e tanto com boca em abertura considerada confortável, quanto com a abertura máxima. Movimento isolado do pilar anterior só foi observado com a boca em abertura máxima, tanto com a língua internalizada, quanto externalizada.

Foram observadas contrações durante as manobras definidas como "com toque" durante a condução do instrumento mas, antes do efetivo toque físico. Foram observados movimentos isolados da língua e movimentos associados da mesma com o pilar anterior e com o palato mole, tanto com a língua internalizada, quanto externalizada e tanto com boca em abertura considerada confortável, quanto com a abertura máxima. Movimento isolado do pilar anterior só foi observado com a boca em abertura máxima, tanto com a língua internalizada, quanto externalizada.

Considerando também como "sem toque" todos os movimentos registrados durante a condução da sonda, verificou-se que o maior percentual de ocorrências de respostas motoras na condição "sem toque" foram para os movimentos isolados da língua em todas as condições testadas mas em especial quando ela se encontrava externalizada.

O percentual de ocorrências de movimentação da língua associado à movimentação do palato mole, seguiu em freqüência a contração isolada da língua e, como esta, mostrou-se presente em todas as condições testadas. Aqui, observa-se algum predomínio nos testes com língua externalizada em abertura máxima da boca.

$\mathrm{O}$ percentual de movimentação da língua associada a movimentos do pilar anterior, nitidamente predomina na condição de abertura máxima da boca e língua externalizada.

A movimentação isolada do pilar, sem que se tenha procedido o efetivo toque, foi admitida como observada em um caso $(2,86 \%)$ com a boca em abertura máxima e língua internalizada, em um caso $(2,86 \%)$ com a língua externalizada e também durante a condução do instrumento em um caso $(2,86 \%)$ com língua internalizada e um caso $(2,86 \%)$ com língua externalizada.

\section{DISCUSSÃO}

Ter observado durante a avaliação dos 18 primeiros voluntários a eventual presença de respostas motoras sem que o efetivo toque do pilar fosse procedido em voluntários com língua externalizada, orientou os autores a analisar as avaliações seguintes (33 voluntários) efetuando observações, em cada um dos indivíduos, com o posicionamento de língua e abertura da boca nas condições que terminaram por ocorrer no primeiro grupo de 18 voluntários, que pode deste modo ser redistribuído e grupado com o segundo, de 33 voluntários.

Não se observou em nenhum dos 51 voluntários desta série, qualquer das respostas admitidas como capazes de serem geradas pelo estímulo mecânico-térmico do pilar anterior, em desacordo com grande parte da literatura consultada ${ }^{(3,8,10,11,18,19)} \mathrm{e}$ em acordo com ALI et al. (2), que utilizando videofluoroscopia e manometria, não observaram, através o estímulo do pilar anterior, resposta contrátil em estruturas envolvidas na dinâmica da deglutição.

As observações positivas registradas por FUJIU et al..$^{(9)}$, através de eletromiografia de superfície, provavelmente se deveram a contrações de postura, abertura da boca e externalização de língua entre outras. O "desejo de deglutir" como considerado por esses autores, não pode ser relacionado a uma resposta reflexa. O desejo é expressão de consciência.

Dependendo do local de estimulação, o reflexo, quando produzido, apresenta princípios fundamentais de resposta como contração ou relaxamento muscular, com força e duração compatíveis com a intensidade do estímulo ${ }^{(16)}$. O reflexo é fenômeno dependente de despolarização do tipo "tudo ou nada"(23, 27). Havendo integridade do circuito neural (receptor, via aferente, núcleos de integração, via eferente e efetor) e atingido o limiar de excitabilidade, o fenômeno reflexo ocorrerá, em frações do segundo, sem o controle da vontade ${ }^{(17)}$. Assim, não é razoável admitir que seja possível estimular o pilar e se tenha o tempo de retirar sonda estimuladora, para a seguir se proceder o fechamento voluntário da boca, necessariamente aberta para o procedimento do toque, para em seguida o reflexo poder se manifestar.

A fase oral, geradora da fase faríngea, se cumpre a partir de uma cavidade necessariamente fechada e pressurizada. $\mathrm{O}$ estabelecimento de uma fase faríngea reflexa produzida pela ejeção oral, com ou sem a presença de conteúdo concreto a estimular mecanicamente receptores localizados nas paredes da orofaringe, permite admitir que a transferência pressórica produzida pela ejeção oral seja a responsável pela resposta faríngea. A distensão pressórica atuaria sobre todo o conjunto de receptores faríngeos e não sobre área específica. Este conceito de resposta reflexa por ação sobre receptores de pressão na parede da faringe atende com propriedade, como já $\operatorname{admitido}^{(4,5,27)}$, ao observado durante as deglutições que, com ou sem a presença do bolo alimentar, deixam ver mecânica semelhante.

Os também admitidos movimentos isolados de elevação da cartilagem tireóide, do palato mole e do pilares anteriores ${ }^{(10,11,18,19)}$, que também não foram observados como resposta ao efetivo estímulo mecânico do pilar anterior, não parecem ser respostas razoáveis de ocorrer isoladamente por estímulo direto do pilares anteriores.

Respostas contráteis isoladas, manifestas por deslocamentos de estruturas ligadas à dinâmica da fase faríngea, produzidas por estímulos locais, poderia ocorrer como resposta a um arco reflexo simples integrado àquele complexo que se observa na 
fase faríngea da deglutição. No entanto, algumas das estruturas admitidas como capazes de responder são de responsabilidade de nervos cranianos ligados à fase voluntária da deglutição, que são assumidos pela coordenação do reflexo da fase faríngea mas, como um todo, como se observa na dinâmica faríngea fisiológica e não como parte que pudesse ocorrer isoladamente.

A elevação da cartilagem tireóide é determinada basicamente pelo músculo tiro-hióideo, inervado pelo plexo cervical, e depende da elevação e fixação do osso hióide, determinada por músculos cuja inervação depende do quinto (nervo trigêmeo) e do sétimo nervo craniano (nervo facial) ${ }^{(5,13,25)}$ e não parece razoável que o estiramento do pilar palatoglosso, inervado pelo plexo faríngeo, gere resposta de elevação da cartilagem tireóide. De igual modo, uma contração inicial no palato mole deve ocorrer por ação do músculo tensor do palato, inervado pelo quinto nervo craniano, para só após ocorrer elevação e contração de seus demais músculos, todos de responsabilidade do plexo faríngeo ${ }^{(5,13,25)}$.

Respostas contráteis do palatoglosso em resposta a seu estiramento mecânico não foram encontradas mas, se presentes, poderiam ser compreendidas como um reflexo de estiramento do músculo palatoglosso, cuja inervação é responsabilidade do plexo faríngeo ${ }^{(5,13,25)}$

É possível que pacientes neurológicos ou pós-cirúrgicos respondam com contrações não encontradas em indivíduos sadios, com controle neural fisiológico, por liberação de inibições presentes em uma cadeia reflexa complexa, como a observada no controle da fase faríngea e, deste modo, justifique a presença de abalos musculares equivocadamente entendidos como respostas funcionais, como referidas pela literatura ${ }^{(3,8,18,19)}$.

Nas manobras definidas como "sem toque" e durante a condução do instrumento, antes do efetivo toque físico, observaram-se movimentos isolados da língua e movimentos associados da mesma com o pilar anterior e com o palato mole, tanto com a língua internalizada, quanto externalizada e tanto com boca em abertura considerada confortável, quanto com a abertura máxima. É possível que algumas dessas respostas estejam, em algum grau, associadas ao reflexo de $\operatorname{gag}^{(21,26)}$. No entanto. a distribuição estatística e as estruturas onde a dinâmica foi observada conduzem a acreditar que essas respostas motoras se devam a contrações voluntárias geradas pela busca da manutenção de abertura da boca e, em especial, da exteriorização da língua.

As considerações efetivadas consolidam-se na observação de que os movimentos de palato e língua, e língua isoladamente, embora tenham sido observados em todas as condições testadas, predominam naqueles com língua externalizada em abertura máxima da boca. Observa-se que também o percentual de movimentação da língua associada a movimentos do pilar anterior, nitidamente predominou na condição de abertura máxima da boca e língua externalizada.

Era expectativa dos autores que o estiramento do músculo palatoglosso, produzido pela abertura da boca e externalização da língua, pudesse rebaixar seu limiar de excitabilidade e que, deste modo, o estiramento produzido pelo toque sobre este músculo, pudesse gerar resposta contrátil isolada do pilar. No entanto, essa resposta contrátil não ocorreu em nenhum dos casos em resposta ao estímulo mecânico-térmico.

A observação em pouco mais de $2,5 \%$ dos casos de movimento isolado do pilar anterior com a boca em abertura máxima e sem toque, levantou a questão de que estas observações não tivessem sido adequadamente efetuadas e estarem em realidade associadas à movimentação de outras estruturas. No entanto, foram mantidas como respostas isoladas por assim terem sido primariamente registradas.

\section{CONCLUSÃO}

Em indivíduos sadios, o estímulo mecânico-térmico produzido sobre os pilares palatoglosso, não é capaz de produzir qualquer resposta motora envolvida na dinâmica reflexa da fase faríngea da deglutição.

\section{AGRADECIMENTOS}

Aos voluntários e à Dra. Ana Maria Furkim pela sugestão do tema e esclarecedoras discussões.

Alvite MFL, Lopes RLC, Costa MMB. Mechanical-thermal stimulation of the palatoglossus pillars. Arq Gastroenterol. 2007;44(3):221-6.

ABSTRACT - Background - The palatoglossus pillars were admitted as the main receptive responsible area by the pharyngeal swallowing reflex produced by food and tongue posterior progression. This concept sustain the mechanical-thermal maneuver used to recovery the committed pharyngeal function. A pharyngeal motor answer by pillar stimulation is common accepted but not unanimously. Aim - To verify the possible pharyngeal motor answers by palatoglossus pillars mechanical thermal stimulation. Method - Healthy volunteers are more able to provide effective reflex answers by pillars stimuli than patients. In this way we evaluated 51 healthy adult volunteers from both sexes reproducing the pillars stimuli using metallic probe. The cold condition was obtained by probe immersion in water maintained to $10^{\circ} \mathrm{C}$. Results and considerations - The study showed that the mechanical thermal stimuli over pillars was not able to produce any active answer linked to the swallowing pharyngeal phase. It is possible that literature observed answers were due to the gag reflex inadequately interpreted or unconscious voluntary contractions effort produced by the opening mouth and tongue externalization during the pillars exposition to execution of the mechanical thermal stimulation maneuvers.

HEADINGS - Pharynx, physiology. Deglutition. Physical stimulation. Gagging. Deglutition disorders. 


\section{REFERÊNCIAS}

1. Ali GN, Laundl TM, Wallace KL, Shaw DW, de Carle DJ, Cook IJS. Influence of mucosal receptors on deglutitive regulation of pharyngeal and upper esophageal sphincter function. Am J Physiol. 1994;267 (4 pt 1):g644-g9.

2. Ali GN, Laundl TM, Wallace KL, de Carle DJ, Cook IJ. Influence of cold stimulation on the normal pharyngeal swallow response. Dysphagia. 1996;11:2-8.

3. Carrara-de-Angelis E, Fúria CL. Tratamento fonoaudiológico em hospital oncológico. Disfagias em câncer de cabeça e pescoço. In: Hernandez AM, Marchesan I, editores. Atuação fonoaudiológica no ambiente hospitalar. Rio de Janeiro: Revinter, 2001. p. 95 .

4. Costa MMB, Moscovici M, Pereira AA, Koch HA. Avaliação videofluoroscópica da transição faringoesofágica (esfíncter superior do esôfago). Radiol Bras. 1993;26:71-80

5. Costa MMB. Anatomia funcional da faringe. In: Petroianu A, editor. A anatomia cirúrgica. Rio de Janeiro: Guanabara Koogan; 1999. p.206-16.

6. Costa MMB. XII Curso de revisão anatômica e videofluoroscópica das bases morfofuncionais da dinâmica da deglutição [material instrucional]. Rio de Janeiro: Laboratório de Motilidade Digestiva/Imagem, Universidade Federal do Rio de Janeiro; 2003. p.47-8.

7. Didio LJA, Anderson MC. The "sphincters" of the digestive system. Anatomical, functional and surgical considerations. Baltimore: Williams \& Wilkins; 1968 p. 20 .

8. Estrela F, Elias V, Martins V. Reabilitação do paciente disfágico em cirurgia de cabeça e pescoço. In: Jacobi SJ, Levy SD, Silva LMC, editores. Disfagia: avaliação e tratamento. Rio de Janeiro: Revinter; 2003. p.245.

9. Fujiu M, Toleikis JR, Logemann JA, Larson CR. Glossopharyngeal evoked potentials in normal subjects following mechanical stimulation of the anterior faucial pillar. Electroencephalogr Clin Neurophysiol. 1994;92:183-95.

10. Furkim AM, Silva RG. Programas de reabilitação em disfagia neurogênica. São Paulo: Frôntis; 1999.

11. Gielow I. Reabilitação fonoaudiológica da disfagia em pós-operatório de cirurgia de cabeça e pescoço. In: Furkim AM, Santini CS, editores. Disfagias orofaríngeas. São Paulo: Pró-Fono, 1999. p.206-8.

12. Guyton AC. Transporte e mistura do alimento no tubo alimentar. In: Tratado de fisiologia médica. 8a ed. Rio de Janeiro: Guanabara Koogan; 1992. p.614-5.

13. Joseph J. Músculos da cabeça e do pescoço - Aparelho locomotor. In: Hamilton WJ, editor. Tratado de anatomia humana. $2^{\text {a }}$.ed. Rio de Janeiro: Interamericano; 1982. p.161-71.
14. Kutchai HC. The gastrointestinal system. In: Berne RM, Levy MN, editors. Physiology. 4th ed. St. Louis: Mosby; 1998. p.598-602.

15. Lazzara G, Lazarus C, Logemann JA. Impact of thermal stimulation on the triggering of the swallowing reflex. Dysphagia. 1986;1:73-7.

16. Lent R. Coordenação dos reflexos e seqüências motoras automáticas. In: Cem bilhões de neurônios - Conceitos fundamentais de neurociência. Rio de Janeiro: Atheneu; 2001. p.369.

17. Le Gross Clark WE. Anatomia do arco reflexo - Sistema nervoso central. In: Hamilton WJ, editor. Tratado de anatomia humana. $2^{\mathrm{a}}$. ed. Rio de Janeiro: Interamericano; 1982. p.539-41

18. Logemann JA. Management of the patient with disordered oral feeding. In: Logemann JA. Evaluation and treatment of swallowing disorders. Texas: Pro-Ed; 1983. p.135-9.

19. Logemann JA. Management of the patient with oropharyngeal swallowing disorders. In: Logemann JA. Evaluation and treatment of swallowing disorders. Texas: Pro-Ed; 1998. p.210-4.

20. Miller AJ. Deglutition. Physiol Rev. 1982;62:129-84.

21. Miller, AJ. Oral and pharyngeal reflexes in the mammalian nervous system: their diverse range in complexity and the pivotal role of the tongue. Crit Rev Oral Biol Med. 2002;13:409-25.

22. Pommerenke WT. A study of the sensory areas eliciting the swallowing reflex. Am J Physiol. 1928;84:36-41.

23. Rhoades R, Pflanzer R. The gastrointestinal system. In: Rhoades R, Pflanzer R, editors. Human physiology. 3rd ed. Philadelphia: Saunders;1996. p.674-7.

24. Sciortino K, Liss JM, Case JL, Gerritsen KG, Katz RC. Effects of mechanical, cold, gustatory, and combined stimulation to the human anterior faucial pillars. Dysphagia. 2003; 18:16-26.

25. Scothorne RJ. Distribuição dos nervos cranianos - Sistema nervoso periférico. In Hamilton WJ, editor. Tratado de anatomia humana $2^{\mathrm{a}}$. ed. Rio de Janeiro: Interamericana; 1982. p.653-75.

26. Stedman TL. Dicionário médico. $25^{\mathrm{a}}$.ed. Rio de Janeiro: Guanabara Koogan; 1996. p. 1110 .

27. Vander AJ, Sherman JH, Luciano DS. Biological control systems - swallowing. In: Vander AJ, Sherman JH, Luciano DS. Human physiology - The mechanisms of the body function. New York: McGraw-Hill; 1975. p.162, 361.

28. Wassilieff N. (1888) citado por: Pommerenke WT. A study of the sensory areas eliciting the swallowing reflex. Am J Physiol. 1928;84:36-41.

Recebido em 25/5/2006 Aprovado em 1/9/2006. 